\title{
EDUCAÇÃO AMBIENTAL E RESÍDUOS SÓLIDOS: UMA VIVÊNCIA ESCOLAR A PARTIR DA METODOLOGIA DA PROBLEMATIZAÇÃO
}

Marinez dos Santos ${ }^{1}$

Maíra Cristina de Oliveira Silva²

Resumo: O presente estudo objetivou sensibilizar estudantes de uma escola de Ensino Fundamental I em Coxim/MS sobre os impactos socioambientais da destinação inadequada dos resíduos sólidos, bem como sobre a importância de promover práticas de reuso, redução, reciclagem e coleta seletiva. Para isso, adotou-se a Metodologia da Problematização com o Arco de Maguerez na qual, em cinco etapas e com abordagens pedagógicas diferenciadas, os alunos puderam realizar uma leitura crítica dos dilemas ambientais em que estão inseridos, propor soluções aos problemas observados e transformar a realidade da instituição.

Palavras-chave: Sensibilização Ambiental; Arco de Maguerez; Consumo Consciente.

Abstract: The present study aimed to sensitize elementary school students in Coxim city about the socio-environmental impacts of inadequate disposal of solid waste and the importance of promoting practices of reuse, reduction, recycling, and selective collection. For this, the Problematization with Maguerez Arc was adopted, in which in five stages and with differentiated pedagogical approaches, students were able to carry out a critical reading of the environmental dilemmas in which they are inserted, propose solutions to the problems observed and transform the school reality.

Keywords: Environmental Awareness; Maguerez Arc; Conscious Consumption.

\footnotetext{
${ }^{1}$ Universidade Estadual de Mato Grosso do Sul (UEMS). E-mail: marinezbioh2o@gmail.com, Link para o Lattes: http://lattes.cnpq.br/3137034024266009

2Universidade Federal de São Paulo (Unifesp). E-mail: maira.silva@unifesp.br, Link para o Lattes: http://lattes.cnpq.br/3234084584727986
} 


\section{Introdução}

A geração desenfreada de Resíduos Sólidos (RS), a falta de conscientização por parte das populações e a disposição de forma incorreta desses materiais vêm causando grandes transtornos para todos os seres vivos do planeta (SIQUEIRA; MORAES, 2009). Os RS são materiais ou substâncias, sólidas ou semissólidas, gerados por atividades industriais, domésticas, hospitalares, agrícolas e de serviços de varrição, incluindo lodos e líquidos, os quais têm particularidades que impossibilitam que sejam lançados nas redes públicas de esgoto e cursos d'águas. Além disso, podem ser definidos e segregados de acordo com: a matéria que os constitui, a sua formação, as atividades que lhes deram origem e, ainda, de acordo com os impactos que podem causar à saúde e ao meio ambiente (ABNT NBR 10.004, 2004; BRASIL, 2010).

No Brasil, a gestão dos RS é um problema enfrentado pela maioria dos municípios. Em 2018, foram gerados, aproximadamente, 79 milhões de toneladas de Resíduos Sólidos Urbanos (RSU) no país, equivalente a um aumento de $1 \%$ comparado com o ano anterior, sendo que destes $92 \%$ foram coletados. De todos os RSU coletados, apenas $59,5 \%$ foram descartados em aterros sanitários e 40,5\% (29,5 milhões de toneladas) foram lançados na natureza de forma inadequada (ABRELP, 2020).

Uma das grandes preocupações atreladas à geração desses materiais é a destinação final. Isso posto, torna-se extremamente importante reunir forças para enfrentar o problema começando por entender melhor como diminuir a geração e de que maneira promover o consumo consciente (BARBOSA, 2008; DIAS, 2004; GOMES et al., 2014). Para que essas ações sejam possíveis, têm sido formalizados vários projetos relacionados à sensibilização da população sobre o meio ambiente, cujo tópico principal é a importância dos recursos naturais para a qualidade de vida das gerações futuras (CARVALHO, 2019; GARCIA et al., 2019; GOUVEIA, 2012).

Ao falar de sensibilização, torna-se fundamental ressaltar que o termo sensibilizar é definido, segundo o dicionário Aurélio (FERREIRA, 2001, p. 630), como $\mathrm{o}$ ato de "[...] tornar sensível; comover; impressionar vivamente". Uma possibilidade de conciliação entre a sensibilização ambiental e a gestão dos resíduos sólidos é a Educação Ambiental (EA), que fornece à sociedade um melhor entendimento com relação ao meio ambiente. Ademais, a EA auxilia a população a tornar-se mais responsável engajando-a a trabalhar de forma coletiva com inovações em torno das questões ambientais para que conheça seus direitos e deveres, se torne crítica e criativa e, também, promova, por meio da sustentabilidade, uma melhor qualidade de vida na Terra (JULIATTO et al., 2011; FRIEDE et al., 2019).

Segundo Reigota (2014), a escola deve ser promotora de conhecimentos e, quando aliada à $E A$, oportuniza processos de aprendizagens sociais e individuais para a consolidação de uma cultura cidadã, inclusiva, pacífica, solidária e responsável ambientalmente e socialmente. No momento 
em que se colocam a EA e a gestão dos RS como peças fundamentais no âmbito escolar, há a possibilidade de os alunos refletirem melhor sobre a importância do meio ambiente e adotarem atitudes ecológicas (LAYRARGUES; LIMA, 2014; NASCIMENTO, MARCHI; PIMENTEL, 2019).

Nesse contexto, o desenvolvimento de práticas de EA para promoção do consumo consciente e a discussão em torno da gestão adequada dos RS na educação básica são de suma relevância. É através desses conhecimentos que os alunos poderão adquirir uma visão crítica e consciente quanto à sustentabilidade e poderão, ainda, atuar como intermediadores dos conhecimentos adquiridos para a sociedade (FRIEDE et al., 2019). Tendo em vista essa pertinência, o presente estudo teve como objetivo sensibilizar os alunos do quarto ano do Ensino Fundamental I, da Escola Estadual Semíramis Carlota Benevides da Rocha, localizada no município de Coxim/MS, sobre os impactos ambientais causados pela destinação inadequada dos resíduos sólidos e sobre a importância de promover boas práticas ambientais, como a não geração, a redução, o reuso, a reciclagem e a coleta seletiva.

Tais práxis são tidas como fundamentais para tornar os alunos cidadãos críticos com relação à gestão dos RS, uma vez que lhes é dada a oportunidade de repensar em diversas formas para se ter um manejo correto dos RSU, possibilitando a diminuição e, consequentemente, atenuando a degradação ambiental na cidade. Além disso, também é mostrada aos alunos a importância da coleta seletiva, que foi implantada em julho de 2020 no município.

\section{Percursos Metodológicos}

Para o desenvolvimento do projeto, a unidade de ensino selecionada foi a Escola Estadual Semíramis Carlota Benevides da Rocha, localizada no município de Coxim/MS. A instituição tem duas unidades localizadas nos bairros Jardim Belas Vista (sede) e Piracema (extensão). Possui 521 alunos, sendo 325 na sede e 196 na extensão. A unidade de ensino selecionada para o desenvolvimento do trabalho foi a Piracema (extensão) que atende somente alunos do Ensino Fundamental I e conta com quatro salas de aula, cantina, sala dos professores e uma quadra de areia sem cobertura (COXIM, 2018; MATO GROSSO DO SUL, 2019).

A escolha dessa unidade deve-se ao fato de que é a única escola que atende os bairros Piracema e Nova Coxim, os quais estão entre os mais carentes do município e são os mais afastados do centro da cidade. As atividades foram desenvolvidas entre os meses de abril a novembro de 2019, somente com os alunos do $4^{\circ}$ ano do período vespertino, durante as aulas de ciências. A sala possuía 22 alunos, com faixa etária de oito a 13 anos.

A fim de alcançar o objetivo proposto, adotou-se como ferramenta para sensibilizar os estudantes a Metodologia da Problematização com o Arco de Maguerez. 


\section{Metodologia da Problematização com o Arco de Maguerez}

O Arco de Maguerez foi elaborado na década de 1970 e desenvolvido por meio de uma Metodologia Baseada em Problemas (MBP). Idealizado por Bordenave e Pereira (1982), o Arco de Maguerez também foi inspirado na pedagogia de Paulo Freire, cujo método de aprendizagem aliava 0 conhecimento transmitido de forma tradicional (conservador) ao conhecimento crítico (progressista), ou seja, um método que procurava entender o que o aluno conhecia sobre determinado assunto e, com base em seu conhecimento prévio, transmitia-lhe o conhecimento teórico (saberes coerentes). Por fim, com a prática, o estudante assimilaria profundamente o que foi ensinado (FREIRE, 1996).

Devido a questões políticas e ideológicas durante a ditadura militar, a obra sobre o Arco de Maguerez só pôde ser publicada em 1989, sendo pouco difundida na época. Em 1992, a metodologia foi aplicada pela primeira vez em um projeto do Centro de Ciências da Saúde da Universidade Estadual de Londrina (UEL) e vem sendo utilizada desde então (COLOMBO, 2007).

Essa metodologia possui cinco etapas: $1^{\circ}$ Observação da realidade, na qual busca-se olhar o local e levantar os problemas existentes; $2^{\circ}$ Pontoschave, em que é realizada uma profunda reflexão com relação ao que foi observado; $3^{\circ}$ Teorização, na qual são demonstradas aos alunos as consequências dos problemas percebidos e visualizados durante a primeira etapa; $4^{\circ}$ Hipótese de soluções, em que os alunos começam a definir formas e propostas criativas e originais para solucionar os problemas levantados; e $5^{\circ}$ Aplicação à realidade, em que coloca-se em prática as propostas definidas, modificando a realidade problematizada (FUJITA et al., 2016).

$O$ desenvolvimento dessa metodologia possibilita aos professores uma maior reflexão com relação às próprias práticas pedagógicas, estimulando-os a tornarem suas aulas mais dialogadas e instigando os alunos a compartilharem suas diferentes formas de pensar (FRANZONI; CRUZ; QUARTIERI, 2019). Partindo da proposta do método do Arco de Maguerez, as atividades apresentadas no trabalho ocorreram em cinco etapas, conforme a Figura 1:

I. Observação da realidade: os alunos visitaram alguns pontos do município (aterro controlado municipal, Córrego Fortaleza e parte interna da escola) para observarem os tipos de resíduos sólidos existentes nos locais. Nessa atividade, foram utilizadas quatro aulas de 50 minutos cada, totalizando dois dias.

II. Pontos-chave: em sala, os alunos foram divididos em grupos para a elaboração de mapas participativos e mapas conceituais, em um total de seis aulas de 50 minutos cada, finalizando em dois dias. A atividade propiciou que os estudantes refletissem sobre os problemas ambientais existentes no município - estado - país - planeta. 


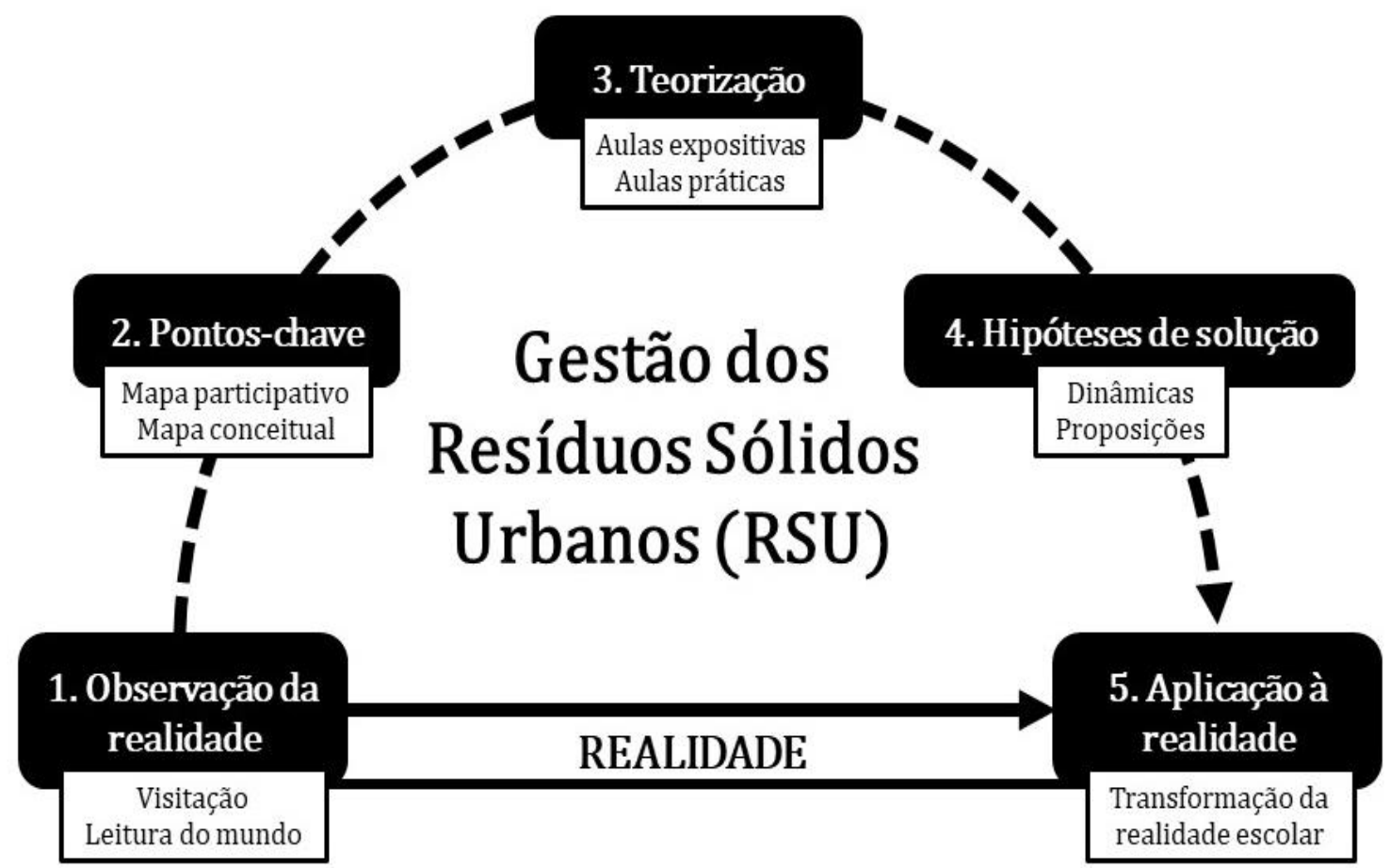

Figura 1: Esquema do Arco de Maguerez adaptado ao presente estudo.

Fonte: autoria própria.

III. Teorização: durante essa etapa, foram passadas três aulas teorizadas com diferentes estratégias de aprendizagem. Foram adotadas aulas expositivas dialogadas e práticas-experimentais com a exposição da coleção biológica didática disponibilizada pela Universidade Estadual de Mato Grosso do Sul (UEMS), que contém animais taxidermizados, insetários e vidrarias com animais conservados em via úmida (álcool $70 \%$ ). Tais práticas possibilitaram um entendimento mais aprofundado a respeito dos problemas socioambientais levantados.

IV. Hipóteses de solução: em seguida, foram utilizadas quatro aulas, sendo estas divididas em dois dias e nas quais os alunos propuseram sugestões de melhorias a serem feitas no ambiente escolar e na comunidade.

V. Aplicação à realidade: foram realizadas algumas atividades no ambiente escolar relacionadas às indicações propostas, em um total de seis aulas divididas em três dias. Com essa prática, foi possível que os alunos aprendessem as várias formas de transformar o que, até o momento, era descartado como algo que não tinha mais utilidade - isto é, "LIXO" - em peças úteis reduzindo, assim, os impactos ambientais causados por esses tipos de materiais. 


\section{Resultados e discussão}

As práticas pedagógicas abordadas pelos educadores implicarão no modo de agir dos alunos futuramente. Portanto, não basta apenas transmitir informações; é preciso, também, abrir espaços para discussões, conceder a oportunidade de os estudantes terem uma visão crítica sobre o assunto e, assim, entenderem que as suas atitudes e ações em relação ao meio ambiente afetarão todos os seres vivos.

Nesse sentido, a Metodologia da Problematização com o Arco de Maguerez ensejou práticas diferenciadas para a aprendizagem significativa possibilitando, aos alunos, a reflexão sobre os impactos socioambientais causados pelo descarte incorreto dos RS na escola, na comunidade e no planeta. Além disso, oportunizou a conscientização e a busca por mudanças de hábitos e de atitudes em prol da sustentabilidade planetária. A seguir, está a descrição dos resultados obtidos em cada etapa do arco.

\section{Etapa I - Observação da realidade}

A observação da realidade permite aos indivíduos construírem conhecimentos por meio de um olhar crítico sobre a realidade. Isso dá a eles a chance de analisarem os problemas existentes, de refletirem sobre esses problemas e de buscarem entender os principais fatores que os determinam, para, em seguida, investigarem formas de transformar a atual realidade (BERBEL; GAMBOA, 2012).

Essa etapa consistiu na visitação dos alunos em três locais, possibilitando que eles conhecessem melhor as formas como estavam sendo descartados os RS produzidos pela população, tanto em áreas afastadas como no ambiente escolar. Para as visitas, os alunos foram divididos em quatro grupos e foi disponibilizado, para cada um deles, um roteiro pré-definido a fim de que fizessem anotações do que estava sendo observado.

O primeiro ponto visitado foi o aterro controlado municipal (Figura 2). Nesse local, até dezembro de 2017, funcionava um lixão a céu aberto e ainda recebe, atualmente, todos os RSU da cidade. $\mathrm{Na}$ entrada, os alunos exploraram a área até onde se localiza a guarita abandonada, observando e anotando os tipos de RS presentes.

Ao adentrarem, foi solicitado que permanecessem no ônibus, por motivo de segurança. Da janela, portanto, puderam observar os diferentes tipos de RS (papéis, plásticos, garrafas, ferros, lâmpadas, restos de ossos, produtos eletrônicos e restos de materiais de construção), bem como a existência de queimadas ilegais, a presença de animais (urubus, garças, ratazanas, cachorros e gatos) e de coletores trabalhando irregularmente, sem nenhum tipo de equipamento de proteção individual ou coletivo. 


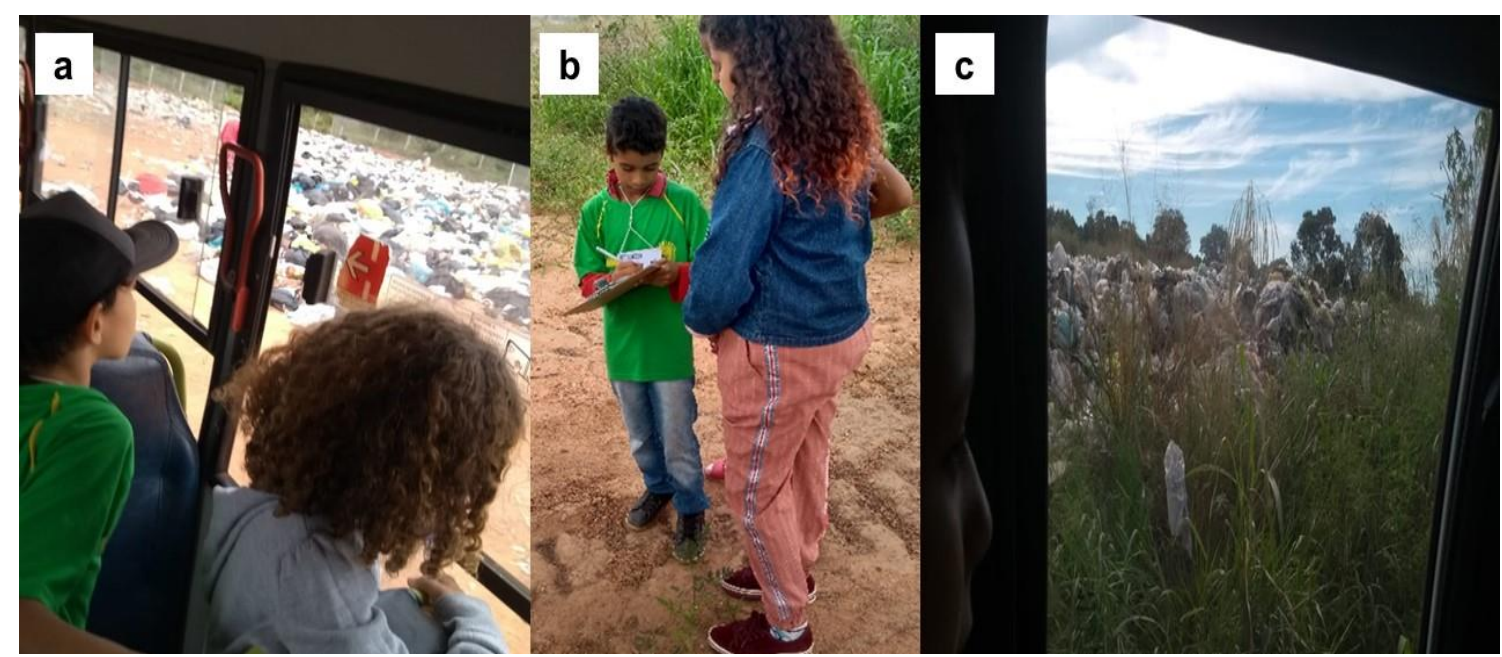

Figura 2: Estudantes durante a visitação no aterro controlado municipal de Coxim, verificando as atividades dos catadores irregulares (a), realizando anotações (b) e observando a disposição dos resíduos (B).

Fonte: autoria própria.

O segundo local visitado foi o Córrego Fortaleza, ponto conhecido no município pela beleza natural e, também, por atrair visitantes que utilizam a área como balneário público. Contudo, junto com os turistas vêm os seus resíduos. Seguindo o roteiro, os alunos desceram do ônibus e observaram e anotaram os tipos de materiais encontrados (garrafas pet, vidros, metais, fraldas descartáveis, sacolas plásticas e copos descartáveis). Além disso, identificaram insetos e larvas no local e notaram a presença de erosão na margem do rio e nas trilhas de acesso ao córrego.

Segundo Zaoual (2009), o aumento da visitação desordenada em áreas naturais e o fato desses locais, por vezes, coincidirem com ecossistemas frágeis causam impactos negativos sobre o ambiente, tais como a destruição da vegetação, a erosão nas trilhas, o lixo deixado pelos visitantes, entre outros. Assim, para garantir a perpetuidade dos ambientes naturais, é imprescindível conhecer os impactos que a visitação pode causar e traçar estratégias para minimizá-los.

Por fim, no pátio da escola, os alunos observaram materiais como papéis, plásticos, garrafas, roupas, canudos, latinhas de refrigerante e tampinhas de garrafas. Quando perguntados sobre o que sentiram ao ver o colégio naquela situação, os estudantes relataram: "vergonha", "tristeza", "mágoa" e "sentimento de que a escola está abandonada". Dessa forma, as anotações sobre os pontos visitados proporcionaram aos alunos uma maior reflexão referente aos problemas observados.

Após as visitas, percebemos o empenho dos alunos, com relação às atividades propostas em aula, e um aumento do interesse em saber como reaproveitar e destinar os tipos de resíduos que foram encontrados, além do interesse em como eles poderiam ajudar para que aquela realidade fosse mudada. A preocupação dos estudantes com relação às áreas mostrou que, 
quando tem contato direto com o que está sendo ensinado, o aluno se sente parte do problema e da solução, isto é, ele se torna mais reflexivo e, consequentemente, se envolve mais com o conteúdo que lhe está sendo apresentado.

\section{Etapa II - Pontos-chave}

Após as visitas, os alunos elaboraram um mapa participativo (Figura 3): uma representação cartográfica produzida conjuntamente com a comunidade inserida na área de estudo, a fim de reforçar as vivências e ideias dessa comunidade. Os mapas participativos possuem grande relevância, pois através desse tipo de mapeamento é possível ter uma interpretação mais efetiva da área estudada (BUGS et al., 2016). No ambiente escolar, o mapa participativo foi de grande importância e permitiu aos estudantes uma avaliação dos principais locais do município em que os RS estavam sendo depositados indevidamente.

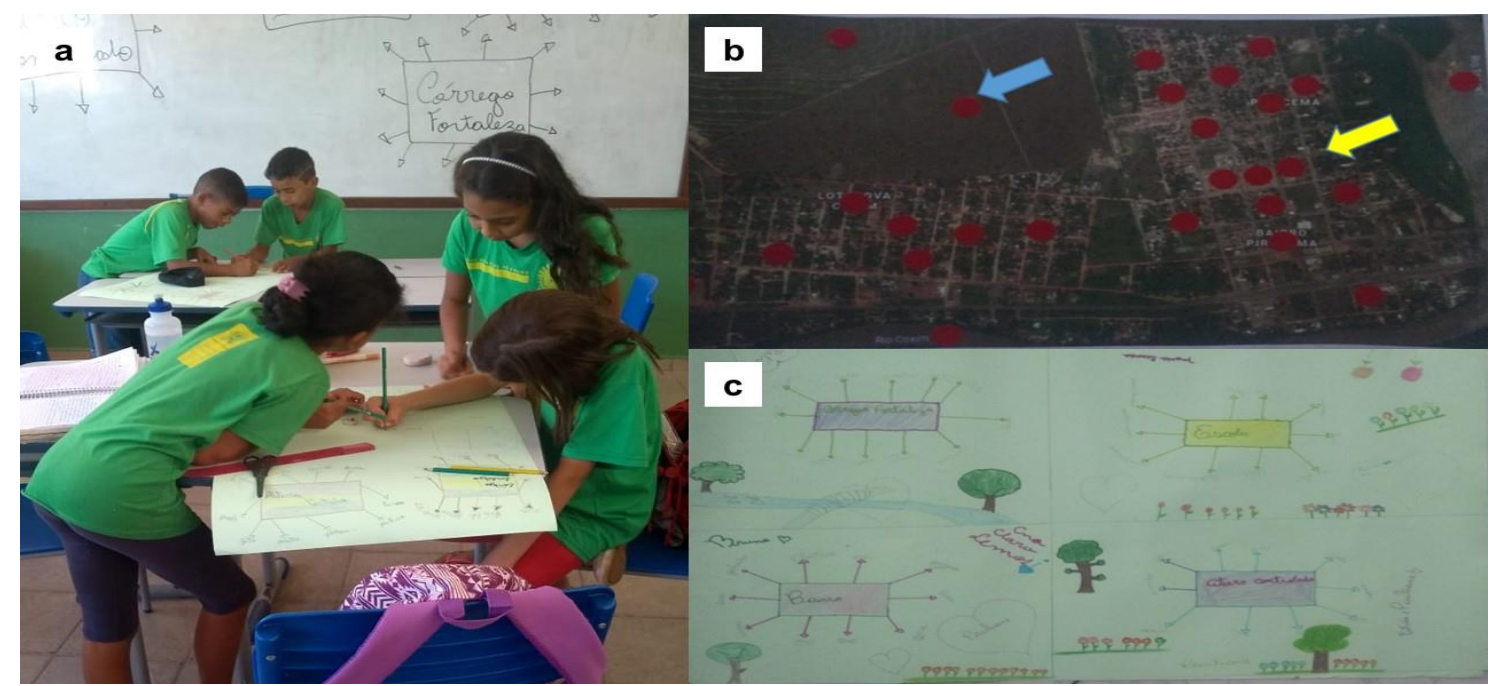

Figura 3: Estudantes elaborando os mapas em sala (a). Na figura 3b está um dos mapas participativos confeccionados pelos grupos e na figura $3 c$ um dos mapas conceituais.

Fonte: autoria própria.

Os mapas foram produzidos a partir de imagens de satélite do Google Earth. Os pontos vermelhos no mapa indicam as áreas que, na percepção dos estudantes, possuem maior quantidade de RS descartados incorretamente; a seta azul representa o aterro controlado municipal; a seta amarela é a localização da escola. Ao pontuarem os locais, os estudantes perceberam que os bairros Piracema e Nova Coxim possuem grande quantidade de marcações, o que lhes trouxe preocupações.

Em seguida, foi elaborado um mapa conceitual sobre os tipos de 
visitados e a quarta caixa é o bairro onde moram; na ponta de cada flecha, estão os principais problemas ambientais existentes no local.

Segundo Moreira (2011), o mapa conceitual é uma prática que possibilita aos indivíduos um entendimento progressivo dos seus aprendizados, já que, além de auxiliar o exercício do pensamento cognitivo, viabiliza, para quem o faz, a organização de pensamentos de forma sequencial, uma vez que há a pontuação, por meio de palavras-chaves, do que foi entendido e aprendido. Assim, com a elaboração conjunta dos mapas e posterior apresentação dos grupos e discussão em sala, os alunos puderam listar os pontos-chave dos problemas observados.

\section{Etapa III - Teorização}

Os estudantes tiveram três aulas expositivas que abordaram os seguintes temas: os diferentes tipos de RS; as formas de praticar os $5 \mathrm{Rs}$ (repensar, reduzir, reciclar, reutilizar e recusar); quem são os principais prejudicados com a destinação inadequada desses materiais; como essas ações voltam para a sociedade e quais as ações da prefeitura de Coxim para mudar a realidade atual.

Para Moreira (2011), o conhecimento teórico é fundamental para o aprendizado que, quando se une a práticas, vídeos, músicas, entre outras formas de transmissão, se torna bem mais significativo aumentando, dessa forma, a capacidade dos alunos armazenarem as informações que lhes foram transmitidas. Nessa perspectiva, a primeira aula iniciou com um vídeo Man, de Steve Cutts, que aborda a forma em que os seres humanos tratam o meio ambiente. Em seguida, foi perguntando "O que são resíduos sólidos?" e, posteriormente, explicada e exemplificada as diferentes categorias de RS e as formas corretas de descarte de cada material.

$\mathrm{Na}$ segunda aula, foram abordados os distintos tipos de impactos socioambientais que a destinação indevida dos RS pode ocasionar, incluindo doenças de veiculação hídrica e transmitidas por vetores. Além disso, também foram apresentados os minidocumentários Mar de plástico e Diário da terra. 0 uso de audiovisual permite que os alunos tenham uma melhor compreensão sobre o tema abordado, além de apresentarem uma maior capacidade de discernimento e de diálogo com os integrantes que participam do processo educacional.

Assim, na terceira aula, os alunos foram sensibilizados ao escutarem a música Toda forma se transforma e ao assistirem ao vídeo Água Brasil. Depois, foram questionados sobre o rumo dos RS que eles próprios geram, dando início ao debate sobre as alternativas para a diminuição, como a compostagem, reciclagem e reutilização desses materiais. Durante a conversa, os alunos souberam de algumas ações da prefeitura, como a implantação da coleta seletiva no município - atividade que possibilita um destino adequado para esses materiais ou uma transformação para algo que possa ser utilizado pela sociedade. 
Após a aula introdutória, os estudantes tiveram uma prática (Figura 4), em que puderam visualizar animais taxidermizados (roedores), animais em vidrarias (vermes e serpentes) e insetos, todos espécimes que são atraídos aos locais onde se encontram indevidamente RS. Ademais, aprenderam a montar composteiras com materiais reciclados, como exemplo do que fazer com os RS orgânicos, e observaram um experimento de filtro feito com garrafas pet, cascalho e areia por meio do qual verificaram que, quando lançado óleo velho na areia, a água percola no solo com dificuldade e contamina o solo e o aquífero. Esse experimento possibilitou aos alunos um entendimento mais abrangente de como a pluma de contaminação polui o lençol freático e quais os impactos que o óleo de cozinha ocasiona ao ter contato com o solo e a água.

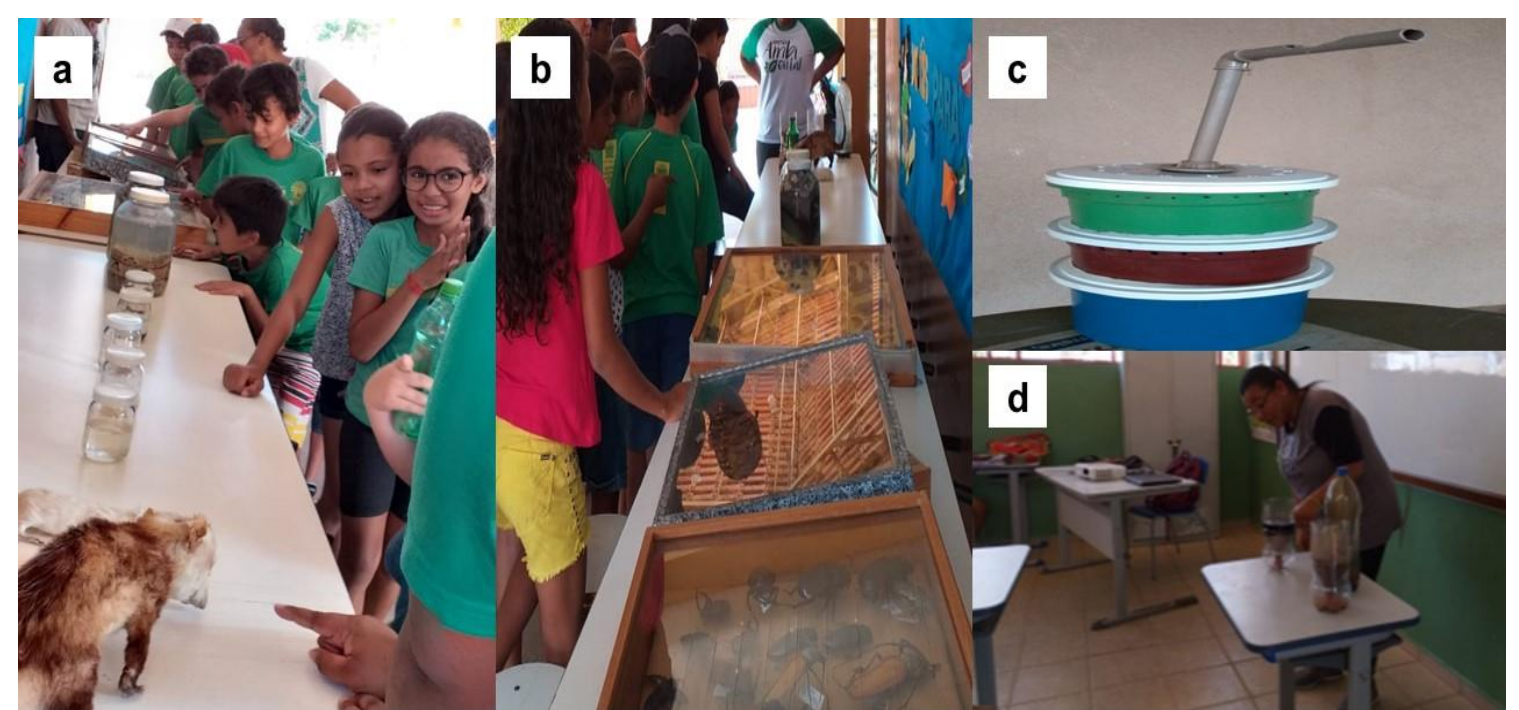

Figura 4: Exibição de animais taxidermizados e em via úmida (a), da coleção entomológica (b), da composteira (c) e do experimento de descarte do óleo (d).

Fonte: autoria própria.

Conforme Queiroz e Guimarães (2017), aulas que possibilitam que os estudantes tenham um contato real com o conteúdo a ser abordado ampliam a compreensão e a percepção, conferindo a esses indivíduos uma maior capacidade de diálogo e de compartilhamento de conhecimentos. Para isso, a proposta pedagógica adotada nas aulas foi a de associar os conhecimentos prévios dos alunos sobre as questões ambientais de modo a manter esse saber vivo, ativo e participativo.

No decorrer das aulas, principalmente nos momentos em que estavam sendo apresentados os vídeos, os alunos compararam o que foi observado durante as visitas com o que estava na teorização e com o conteúdo trabalhado na disciplina de ciências. Em todas as aulas, foi nítido o entusiasmo ao verem os animais, o que fez com que se interessassem e participassem ativamente das atividades, com perguntas e questionamentos. 


\section{Etapa IV - Hipóteses de soluções}

Segundo Colombo (2007), nessa etapa é preciso estimular a criatividade e originalidade, tornando possível transformar a realidade em algo melhor e, consequentemente, aprender com ela. Assim, após os alunos terem um maior aporte teórico, foram realizadas dinâmicas em que um participante sorteava uma carta e os demais alunos deveriam fazer o que era solicitado. Alguns cartões continham questões de verdadeiro/falso sobre o conteúdo ministrado; outros estavam com mímicas, desafiando o aluno a fazer gestos para que os colegas adivinhassem a resposta; e, em algumas outras cartas, estava escrito a palavra "desenho". De posse destas, os estudantes solicitavam a ajuda de colegas para desenharem no quadro e os demais teriam que acertar quais eram os tipos de RS. Além dessas atividades, foi realizada uma dinâmica de construção de teia com barbante, em que os alunos falavam um tipo de RS e passavam o barbante para o próximo colega, formando uma teia - para desfazê-la, o estudante teria que propor soluções ambientalmente adequadas para minimização ou destinação correta.

No início das atividades, alguns alunos se sentiram envergonhados, porém, com o decorrer da aula, foram se desinibindo e logo se empolgaram com os exercícios propostos. Todos os estudantes participaram das dinâmicas, o que tornou a aula bastante produtiva e com maior interação entre eles. Por fim, foi solicitado aos alunos que escrevessem sugestões de melhorias para serem feitas no ambiente escolar (Figura 5) e na comunidade, a fim de diminuir a degradação ambiental naquelas áreas em decorrência do descarte de forma incorreta dos RSUs.

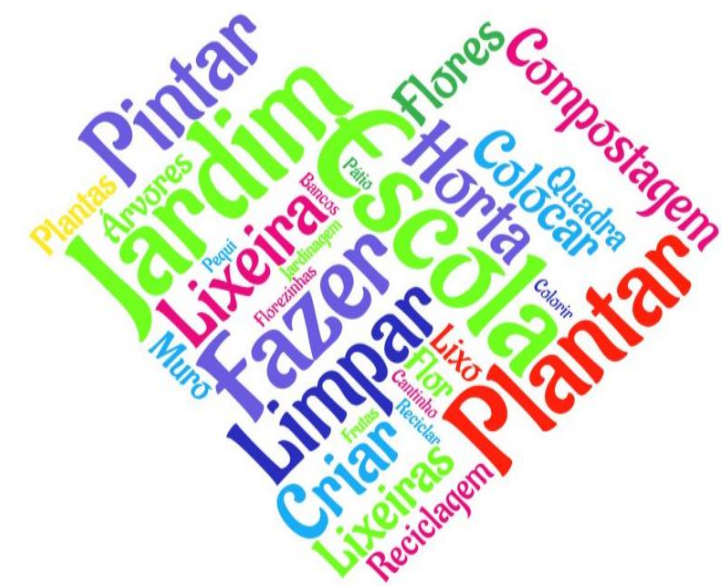

Figura 5: Nuvem de palavras concebida a partir das sugestões dos alunos.

Fonte: autoria própria.

Dentre as principais propostas apresentadas para o ambiente escolar, destacam-se: o plantio de árvores no entorno e dentro da instituição; a confecção de lixeiras para colocar no pátio; a construção de um jardim na escola; a pintura da escola; a construção de uma área de convivência, onde pudessem se sentar para ler; e, por fim, a confecção de brinquedos com materiais reciclados.

revista brasileira educação ambiental 


\section{Etapa V - Aplicação à realidade}

Para Colombo (2007), a aplicação à realidade possibilita exercitar soluções para os problemas levantados, permitindo um maior comprometimento para que os fatos observados no primeiro momento não possam voltar. Essa etapa permitiu aos alunos colocarem em prática algumas de suas sugestões e podendo, assim, transformar o ambiente escolar. A execução das ações sugeridas pelos alunos ocorreu em quatro partes:

- Mutirão de limpeza da escola: os alunos ficaram surpresos com a quantidade de RS encontrados (quatro sacos de lixo preto de 100 litros) e se propuseram a fazer a limpeza mais vezes para que a escola permaneça limpa. Após essa atividade, foi solicitado para a prefeitura a limpeza e carpina do terreno da escola (Figura 6);

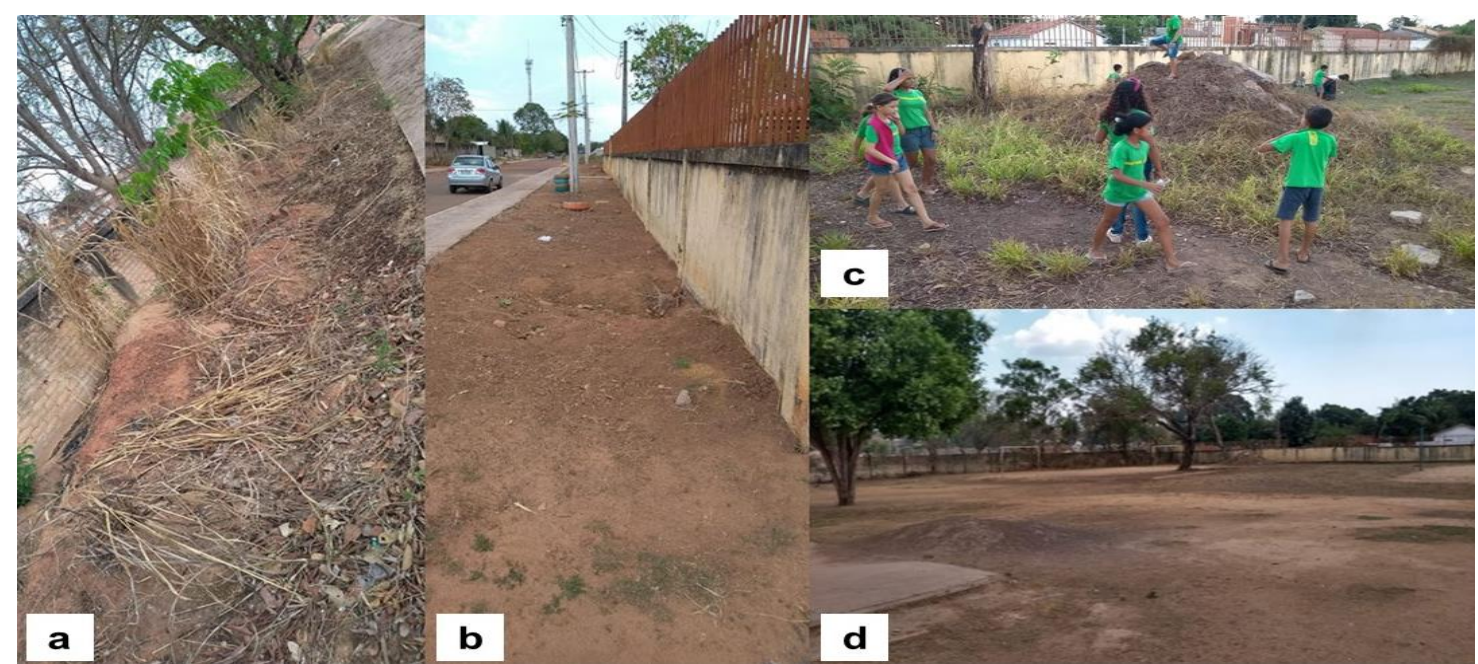

Figura 6: Situação da escola antes (a e c) e após (b e d) a limpeza realizada pelos alunos (c) e pela prefeitura.

Fonte: autoria própria.

- Confecção de lixeiras: essa etapa foi essencial, pois motivou os alunos a usarem as lixeiras produzidas e a conversarem com os colegas sobre a importância de sua utilização (Figura 7a);

- Construção de brinquedos com materiais reciclados: atividade em que os estudantes aprenderam como podem reciclar materiais que julgavam não ser mais úteis (Figura $7 b$ ); e

- Plantio de vários tipos de mudas na escola (ipês, cedro, pinheiros, palmeiras, entre outras): durante essa atividade, todos os alunos se empenharam e se prontificaram a continuar cuidando das mudas (Figura 7c). 


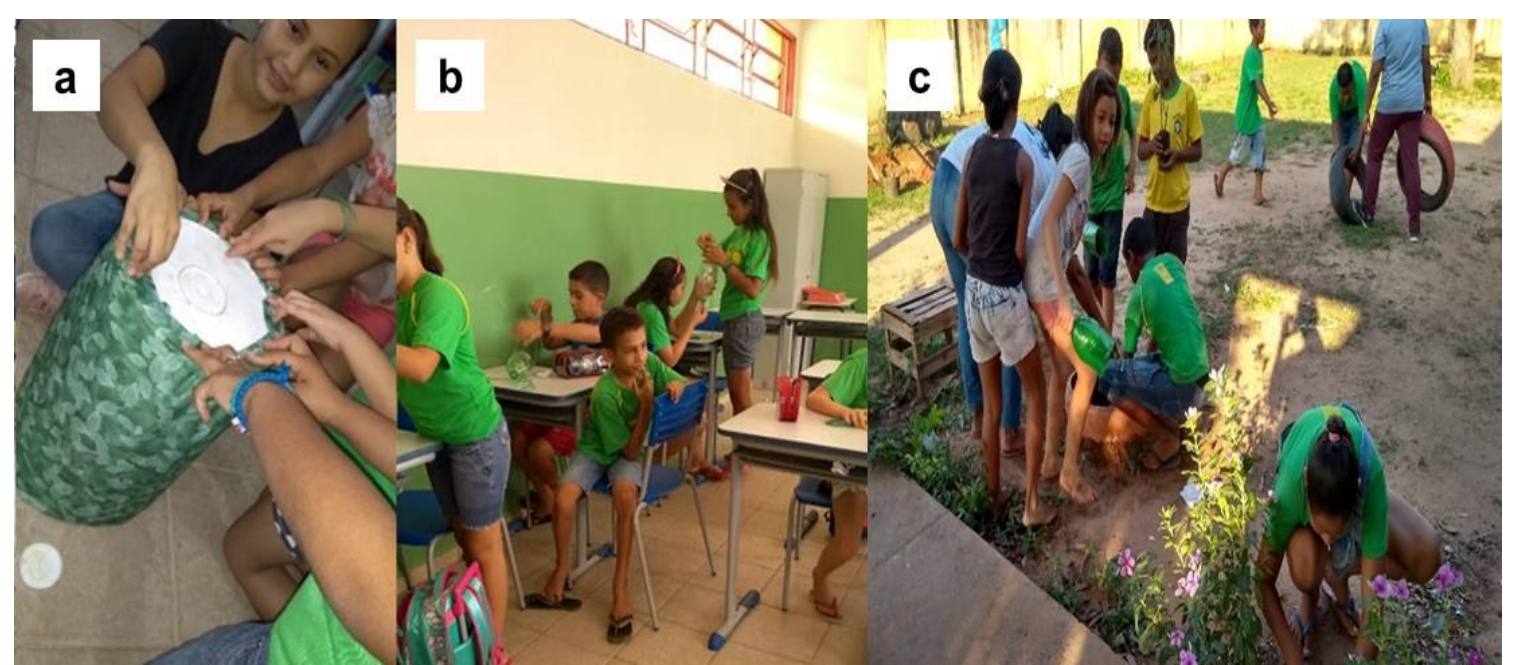

Figura 7: Alunos produzindo lixeiras (a), brinquedos com materiais recicláveis (b) e plantando mudas e flores (c) na escola.

Fonte: autoria própria.

Com o desenvolvimento das atividades propostas pelos alunos, foi possível perceber que o jeito de abordar a Educação Ambiental nas escolas repercute diretamente no entendimento dos estudantes, bem como em sua forma de agir diante da informação transmitida. No decorrer do trabalho, percebeu-se uma maior conscientização por parte dos alunos com relação à conservação ambiental e uma preocupação em transmitir o que estava sendo aprendido para amigos e familiares.

Para Martins et al. (2018), a importância da metodologia da problematização com o Arco de Maguerez não está apenas nas etapas a serem cumpridas, mas sim na importância das mudanças ocorridas do início ao fim do arco. Do momento em que notam o problema até o momento em que conseguem solucioná-los, os participantes alcançam etapas que contribuem tanto para seu crescimento intelectual quanto social.

Ao término do trabalho, ao ser questionada sobre de que maneira avalia a metodologia empregada, a coordenadora da escola respondeu: "a metodologia foi bastante válida, pois se nota um grande progresso com os alunos em relação à conservação da limpeza do ambiente escolar e à preocupação dos estudantes em passar as informações obtidas para outros alunos". Além disso, a coordenadora demonstrou interesse em adotar a metodologia da problematização na escola em outras disciplinas e com diferentes temas.

Com o relato da coordenadora, vale destacar dois pontos importantes. $\mathrm{O}$ primeiro diz respeito à mudança de postura dos estudantes com relação à limpeza da escola - acreditamos que tal transformação é reflexo do surgimento de uma genuína preocupação com os impactos socioambientais do descarte incorreto dos resíduos sólidos. Segundo Teixeira (2018), a partir do momento em que os estudantes se inquietam com as questões ambientais, aumenta-se a 
possibilidade de conservação da área em que estão inseridos, pois passam a atuar como cidadãos ativos.

O segundo ponto é que o Arco de Maguerez abre um leque de oportunidades para ser aplicado em distintos temas, componentes curriculares, níveis e modalidades de ensino, além de poder ser aliado a outras metodologias e práticas pedagógicas. Assim, embora tenhamos utilizado as aulas de ensino de ciências, as atividades foram desenvolvidas em uma abordagem multi, trans e interdisciplinar. Isso ocorreu, visto que procurou-se romper as barreiras entre todas as disciplinas possibilitando aos estudantes um conhecimento com características transversais e integradas, em que todas as fronteiras, que antes existiam entre uma disciplina e outra, deixam de existir e aglutinam diferentes competências e formas de pensar.

Fujita et al. (2016) afirmam que transformar as práticas tradicionais em práticas transformadoras provoca nos alunos a construção de novos saberes e fazeres. Partindo desses princípios, atividades que incluam Educação Ambiental e transformam a realidade atual em algo novo fazem com que os estudantes queiram repassar o conhecimento adquirido contribuindo, assim, para a construção de uma sociedade ambientalmente crítica e envolvida com a sustentabilidade.

Para o processo de sensibilização e de conscientização dos alunos, as atividades também contaram com as orientações do Projeto Político Pedagógico (PPP) da instituição de ensino, cujo objetivo condiz com as ações propostas, uma vez que ambos visam formar sujeitos críticos, participativos e responsáveis, além de buscar envolver toda a comunidade e propiciar aos estudantes situações que os façam pensar e realizar atividades de forma coerente. O PPP escolar busca desenvolver ações que contribuam para a fortificação dos conhecimentos dos estudantes, o que tornou este trabalho de grande acuidade tanto para os alunos quanto para cumprimento dos objetivos da escola.

\section{Conclusões}

Os danos socioambientais causados pelo descarte incorreto dos resíduos sólidos têm sido uma das grandes preocupações da atualidade. Quando a população é conscientizada e inserida diretamente na gestão dos resíduos sólidos, a chance de se ter um ambiente ecologicamente equilibrado é bem maior. Para que isso se torne possível, é necessário não apenas falar o que é preciso fazer, mas, sobretudo, mostrar como fazer, o que fazer e quais são os benefícios por trás dessas atividades.

Por isso, tem se investido cada vez mais em metodologias nas quais os estudantes se sintam completamente envolvidos no processo de aprendizagem. Dessa forma, para o desenvolvimento deste trabalho, foi utilizada a Metodologia de Problematização com o Arco de Maguerez, que buscou, em cinco etapas, fazer com que fossem compreendidos os problemas 
ambientais da cidade, procurando, igualmente, maneiras de solucioná-los. Para tanto, os estudantes realizaram visitas técnicas em que puderam observar os tipos de resíduos sólidos existentes nos locais e a forma como estes estavam sendo descartados. Em seguida, foram elaborados mapas participativos e conceituais e, subsequentemente, realizadas aulas expositivas e práticasexperimentais.

Posteriormente, os estudantes participaram de dinâmicas e proposições de soluções aos problemas socioambientais apresentados, finalizando com a transformação da realidade escolar por meio de ações práticas. Desse modo, por meio de uma metodologia inovadora, o trabalho buscou contribuir para a formação de sujeitos críticos, criativos, participativos e capazes de enfrentar os desafios causados pela destinação incorreta dos resíduos sólidos e de desenvolver valores e atitudes que irão intervir na realidade da comunidade.

\section{Referências}

ASSOCIAÇÃO BRASILEIRA DE EMPRESAS DE LIMPEZA PÚBLICA E RESÍDUOS ESPECIAIS (ABRELPE). Panorama de resíduos sólidos no Brasil 2018/2019. Disponível em: <http://abrelpe.org.br/panorama/>. Acesso em: 22 mai. 2020.

ASSOCIAÇÃO BRASILEIRA DE NORMAS TÉCNICAS (ABNT). ABNT NBR 10004: Resíduos sólidos - Classificação. Rio de Janeiro, 2004, p. 71.

BARBOSA, L. C. Políticas públicas de Educação Ambiental numa sociedade de risco: tendências e desafios no Brasil. Anais do IV Encontro Nacional da Anppas, v. 4, n. 5, p. 1-21, 2008.

BERBEL, N. A. N.; GAMBOA, S. A. S. A metodologia da problematização com - Arco de Maguerez: uma perspectiva teórica e epistemológica. Filosofia e Educação (Online), V. 3, N. 2, 2012.

BORDENAVE, J. D.; PEREIRA, A. M. Estratégias de ensino aprendizagem. 4. ed. Petrópolis: Vozes, 1982.

BRASIL. Lei $n^{\circ}$ 12305, de agosto de 2010. Institui a Política Nacional de Resíduos Sólidos; altera a Lei no 9.605, de 12 de fevereiro de 1998; e dá outras providências. Diário Oficial da República Federativa do Brasil, Poder Executivo, Brasília DF.

BUGS, G.; RAUBER, A.; ISOLAN, F. B. Ferramentas SIG - Sistemas de Informações Geográficas para o Planejamento Participativo. In: FURTADO, A.; PEREIRA, A.; PARENZA, C.; GERMANO, L.; COSTER, R.; RANGEL, R.; BASSANI, B. (Org.). Democracia nas Cidades e as Grandes Transformações Urbanas. Porto Alegre: Editora da Cidade, 2016. 
CARVALHO, D. S.; GARCIA, T. V. L.; LIMA, J. P. S. Resíduos sólidos no brasil: uma conexão com a relação homem/natureza, sustentabilidade e Educação Ambiental. Educação Ambiental em Ação, v. 68, 2019.

COLOMBO, A. A. A Metodologia da Problematização com o Arco de Maguerez e sua relação com os saberes de professores. Semina: ciências sociais e humanas, v. 28, n. 2, p. 121-146, 2007.

COXIM. 2018. Censo Escolar/INEP 2018. Coxim, MS. Disponível em: $<$ tttps://www.qedu.org.br/escola/255101-ee-semiramis-carlota-benevides-darocha/aprendizado>. Acesso em: 24 abr. 2020.

DIAS, G. F. Educação Ambiental: princípios e práticas. Editora Gaia LTDA. $6^{\circ}$ edição. p. 1-551, 2004.

FERREIRA, A. B. H. Mini Aurélio: dicionário de língua portuguesa. Editora Nova Fronteira. $4^{\circ}$ edição. p. 1-790, 2001.

FRANZONI, P. G. R.; CRUZ, R. P.; QUARTIERI, M. T. Ensinando a metodologia da problematização com o Arco de Maguerez a partir da estratégia World Café. Reflexão e Ação, v. 27, n. 3, p. 191-207, 2019.

FREIRE, P. Pedagogia da autonomia: saberes necessários a prática educativa. Paz e terra. $25^{\circ}$ edição, 1996.

FRIEDE, R. R.; REIS, D. S.; AVELAR, K. E. S.; MIRANDA, M. G. Coleta seletiva e Educação Ambiental: reciclar valores e reduzir o lixo. Educação \& Formação, v. 4, n. 11 mai/ago, p. 117-141, 2019.

FUJITA, J. A. L. M.; CARMONA, E. V.; SHIMO, A. K. K.; MECENA, E. H. Uso da metodologia da problematização com o Arco de Maguerez no ensino sobre brinquedo terapêutico. Revista Portuguesa de Educação, v. 29, n. 1, p. 229258, 2016.

GARCIA, E. V.; VIESBA, L. M. V.; ROSALEN, M. S. Educação Ambiental para a sustentabilidade: formação continuada em foco. Humanidades e tecnologia (FINOM), v. 1, n. 16, p. 10-24, 2019.

GOMES, M. H. S. C.; OLIVEIRA, E. C.; BRESCIANI, L. P.; PEREIRA, R. S. Política Nacional de Resíduos Sólidos: Perspectivas de Cumprimento da Lei 12.305/2010 pelos municípios brasileiros, paulistas e da região do ABC. Revista de Administração da UFSM, v. 7, p. 93-110, 2014.

GOUVEIA, N. Resíduos sólidos urbanos: impactos socioambientais e perspectiva de manejo sustentável com inclusão social. Ciência; saúde coletiva, v. 17, p. 1503-1510, 2012.

JULIATTO, D. L.; CALVO, M. J.; CARDOSO, T. E. Gestão integrada de resíduos sólidos para instituições públicas de ensino superior. Revista Gestão Universitária na América Latina-GUAL, v. 4, n. 3, p. 170-193, 2011. 
LAYRARGUES, P. P.; LIMA, G. F. C. As macrotendências político-pedagógicas da Educação Ambiental brasileira. Ambiente \& Sociedade, v. 17, n. 1, p. 2340, 2014.

MARTINS, M. M. B.; SOUZA, S. L.; CARVALHO, R. C.; AGUIAR, M. G. G.; ALVES, A. B. L.; Souza, G. K. O. Prevenção ao uso de álcool e outras drogas por adolescentes através do arco de Charles Maguerez. CIAIQ 2, 2018.

MATO GROSSO DO SUL. Coordenadoria Regional de Educação - CRE-4. E. E. Semíramis Carlota Benevides da Rocha. Disponível em: $<$ http://www.cre4coxim.sed.ms.gov.br/coxim/>. Acesso em: 28 mai. 2019.

MORAES, M. A. C. Mapas Mentais como significação do conhecimento: um estudo de caso aplicado à Educação Infantil. Anais do IV Congresso Nacional de Educação: CONEDU, 2017.

MOREIRA, M. A. Aprendizagem significativa: um conceito subjacente. Aprendizagem Significativa em Revista, V1(3), pp. 25-46, 2011.

NASCIMENTO, M. C. P.; MARCHI, C. M. D. F.; PIMENTEL, P. C. B. Proposição de metodologia em Educação Ambiental para minimizar impactos de resíduos sólidos em ecossistema de manguezal. PerCursos, v. 19, n. 41, p. 158-178, 2019.

QUEIROZ, E. D.; GUIMARÃES, M. O trabalho de campo em unidades de conservação como ambiente educativo e estratégia pedagógica fundamental para uma formação diferenciada em Educação Ambiental. Revista de Políticas Públicas, v. 20, p. 421-426, 2017.

REIGOTA, M. O que é Educação Ambiental. São Paulo: Brasiliense, 2014.

SIQUEIRA, M. M.; MORAES, M. S. Saúde coletiva, resíduos sólidos urbanos e os catadores de lixo. Ciência; Saúde Coletiva, v. 14, p. 2115-2122, 2009.

TEIXEIRA, T. Y. A. A Educação Ambiental e a biodiversidade: educar um cidadão é renovar sua consciência. Biodiversidade, v. 17, n. 2, 2018.

ZAOUAL, H. Do turismo de massa ao turismo situado. In: BARTHOLO, R.; SANSOLO, D.; BURSZTYN, I. (Orgs.). Turismo de base comunitária: diversidade de olhares e experiências brasileiras. Brasília: Letra \& Imagem, 2009. p.55-75. 